\title{
SORODIAGNÓSTICO DA DOENÇA DE CHAGAS: NOVO REAGENTE PARA O TESTE DE HEMAGLUTINAÇÃO INDIRETA (THAI ${ }^{\mathrm{IAL}}$ )
}

\author{
Álvaro Toshiaki Sasaki, Sumie Hoshino-Shimizu, Paulo Mutuko Nakamura, \\ Adelaide José Vaz, Eide Dias Camargo e Marcos Vinícius da Silva
}

\begin{abstract}
Reagente novo destinado ao teste de hemaglutinação indireta, THAI IAL, foi padronizado, utilizando hemácias de ganso, como suporte inerte, para o diagnóstico de campo da tripanosomiase americana. O objetivo foi o de substituir o reagente liofilizado ou congelado de THAl produzido rotineiramente, empregando hemácias humanas, no Instituto Adolfo Lutz (São Paulo, Brasil). O reagente padronizado apresentou longa estabilidade em suspensão líquida, e foi avaliado em 137 anostras de soros de pacientes chagásicos e não chagásicos, ein THAI ${ }^{I A L}$. O desempenho diagnóstico deste teste foi semelhante ao de THAI utilizando hemácias humanas e ao de THAI de procedencia comercial. A sensibilidade foi 1,00 , especificidade 0,98 , valores de preditivo positivo 0,96 , e negativo 1,00 . As diferentes partidas de reagente sucessivamente produzidas demonstraram ser reprodutiveis em método de controle de qualidade. O novo reagente é mais econômico que o anterior, de fácil preparo e aplicável aos estudos soroepidemiológicos.
\end{abstract}

Palavras-chaves: Hemácias de ganso. Reagente de THAI. Doença de Chagas. Sorodiagnóstico.

A doença de Chagas (tripanosomíase americana) no Brasil é endêmica, constituindo um dos sérios problemas de saúde pública. Nas zonas rurais, a doença é transmitida principalmente através de triatomídeos, enquanto nas zonas urbanas a transmissão ocorre por transfusão sanguínea ou transplante de órgãos, em virtude do contingente de migrantes procedentes dessas áreas endêmicas para as grandes cidades ${ }^{24}$.

O diagnóstico da infecção por Trypanosoma cruzi apoia-se em dados de exames laboratoriais, sendo a maioria baseada na demonstração de anticorpos específicos séricos. Diversos testes sorológicos foram descritos ${ }^{27}$ para finalidade diagnóstica, contudo testes econômicos e práticos são preferidos para estudos populacionais.

$O$ reste de hemaglutinação indireta (THAI), a

Instituto Adolfo Lutz, Faculdade de Ciências Farmacêulicas da Universidade de São Paulo e Inslituto de Infectologia Emíio Ribas, São Paulo, SP.

Auxílio financeiro da Fundação Nacional de Saúde/Ministério da Saúde.

Endereço para correspondência: Dr. Álvaro Toshiaki Sasaki. Av. Dr. Arnaldo 35I, C. César, 01246-902 São Paulo, SP. Fax: (0l1) 8.53-3505.

Recebido para publicação em 28/12/95 par de alguns outros, destaca-se por apresentar características desejáveis aos estudos epidemiológicos. Este teste, com o decorrer do tempo, sofreu modificações quanto ao tipo de antígeno 1626 , tratamento de hemácias com aldeído $^{4}{ }^{15}$, e estabilização do reagente ${ }^{9} 16$.

No Instituto Adolfo Lutz (Secretaria de Estado da Saúde de São Paulo), reagente para o THAI sob forma liofilizada ou congelada vinha sendo produzido, rotineiramente, entre outros reagentes imunobiológicos, para prover sua rede de laboratórios regionais no Estado de São Paulo. Este reagente no entanto, deixou de ser produzido por empregar hemácias humanas, não recomendáveis segundo a recente portaria do Governo Federal ${ }^{20}$.

Em virtude da escassez de informação sobre o uso de hemácias de aves para o preparo do reagente de THAI na literatura, o presente trabalho abordou o estudo das hemácias de ganso como suporte inerte para a produção do referido reagente. Ademais, tentativas foram feitas para torná-lo estável mesmo sob forma de suspensão líquida, desde que o reagente anterior encarecia por exigir liofilização ou então era pouco prático, quando mantido congelado. 
Sasaki AT, Hoshino-Shimizu S, Nakamura PM, Vaz AJ, Camargo ED, Silva MV. Sorodiagnóstico da doença de Chagas: novo reagente para o teste de hemaglutinação indireta (THAIIAL). Revista da Sociedade Brasileira de Medicina Tropical 29:137-144, mar-abr, 1996.

\section{MATERIAIS E MÉTODOS}

$\mathrm{Na}$ padronização do reagente para o teste de hemaglutinação indireta (THAI $\left.{ }^{\mathrm{IAL}}\right)$, diferentes fatores interferentes tais como, substâncias químicas, concentração, $\mathrm{pH}$, e outros, foram estudados em virtude de hemácias de aves apresentarem várias características físico-químicas que diferiram das hemácias humanas em nossa experiência ainda preliminar. Os itens abaixo relacionados constituem os dados definitivos obtidos após a optimização das condições de preparo do reagente.

\section{Extrato antigênico}

Formas epimastigotas da cepa $Y$ de Trypanosoma cruzi ${ }^{23}$, cultivadas em meio líquido (LIT) ${ }^{10}$ qurante 8 dias a $27^{\circ} \mathrm{C}$, foram empregadas para a obtenção do antígeno solúvel, baseando-se na metodologia citada anteriormente ${ }^{16}$. Em resumo, cerca de $100 \mathrm{mg}$ (peso úmido) do parasita foram tratados com $15 \mathrm{ml}$ de $\mathrm{NaOH} 0,15 \mathrm{M}$, e submetidos à sonicação por três ciclos de 30 segundos $(15 \mathrm{~Hz}, 1,5 \mathrm{~mA})$. Após a neutralização do extrato antigênico, com $\mathrm{HCl} 2 \mathrm{M}$, foi dividido em alíquotas de $1 \mathrm{ml}$ e conservado a $-20^{\circ} \mathrm{C}$.

A concentração protéica foi determinada segundo Lowry e cols ${ }^{19}$, tendo albumina bovina (Sigma Chemical Co., USA) como padrão.

\section{Hemácias}

Hemácias de ganso macho foram tratadas baseando-se no processo previamente descrito ${ }^{15}$ para eritrócitos de mamíferos, com algumas modificações. Sangue de gansos sadios adultos machos foi colhido em igual volume de solução anticoagulante e conservante (solução de Alsever) ${ }^{5}$. A um volume de suspensão de hemácias a $10 \%$ $(\mathrm{v} / \mathrm{v})$ foi adicionado igual volume de $\mathrm{p}$-formaldeído (Becto, Brasil) a $10 \%(\mathrm{p} / \mathrm{v})$ em PBS-1 ( $\mathrm{NaCl}$ $0,15 \mathrm{M}, \mathrm{Na}_{2} \mathrm{HPO}_{4} \quad 0,007 \mathrm{M}$ e $\mathrm{NaH}_{2} \mathrm{PO}_{4} 0,003 \mathrm{M}$ pH 7,2), e a mistura mantida a $37^{\circ} \mathrm{C}$ por 18 horas, sob agitação ocasional. As células tratadas foram centrifugadas, lavadas quatro vezes, ressuspensas a $20 \%$ em PBS- 1 contendo $4 \%(\mathrm{p} / \mathrm{v})$ de $\mathrm{p}$-formaldeído, e armazenadas a $4^{\circ} \mathrm{C}$.

\section{Sensibilização das hemácias com extrato antigênico}

A sensibilização das hemácias formolizadas foi baseada na metodologia utilizada por Camargo e cols $^{8}$, com algumas modificações. Após a sensibilização e tratamento com glutaraldeído, as hemácias foram lavadas e ressuspensas a 1,5\% (v/v) em solução de leite desnatado (leite Molico, Nestlé) a $5 \%$ em PBS-2 ( $\mathrm{NaCl} 0,073 \mathrm{M}, \mathrm{Na}_{2} \mathrm{PO}_{4}$ $0,027 \mathrm{M}, \mathrm{KH}_{2} \mathrm{PO}_{4}$ 0,049M, pH 6,4), mantendo a suspensão sob agitação por duas horas à temperatura ambiente. Após outro ciclo de lavagens, o sedimento de hemácias foi ressuspenso a $1,5 \%$ em solução estabilizante complexa (leite desnatado $0,9 \%$, glicina $0,178 \mathrm{M}$, merthiolato $0,001 \mathrm{M}$, glutamato de sódio $0,036 \mathrm{M}$, tioglicolato de sódio $0,036 \mathrm{M}$ e glicerol a 40\%, em PBS-2).

Como agente anti-espumante, dimetilpolisiloxane (silicone) a $0,08 \%$ foi acrescentado à suspensão de hemácias sensibilizadas.

As concentrações ótimas de antígeno $(9 \mu \mathrm{g} / \mathrm{ml})$ e ácido tânico $(0,1 \mathrm{mg} / \mathrm{ml})$ (Riedel-de-Haen, Germany) utilizados foram determinadas por titulação em bloco empregando soros padrão positivo e negativo ${ }^{345}$, preparado com soros de pacientes chagásicos e não chagásicos. Em paralelo, foram preparadas hemácias-controle, diferindo pela substituição do antígeno por PBS-2 no processo de sensibilização. Os reagentes foram divididos em alíquotas de $10 \mathrm{ml}$ e conservados a $4^{\circ} \mathrm{C}$ ou $37^{\circ} \mathrm{C}$.

\section{Teste de hemaglutinação indireta (HAI)}

O teste foi realizado em placas de microtitulação de poliestireno, com fundo em "V" (Inlab, Brasil), adicionando-se $25 \mu \mathrm{l}$ das amostras de soro em estudo, diluídas em série e ao dobro, a partir de 1:2 até 1:4096 em PBS-2, eadicionando-se $25 \mu$ l do reagente de hemácias sensibilizadas. As placas foram agitadas mecanicamente por 2 a 3 minutos, e incubadas em câmara úmida por 60 minutos à temperatura ambiente em local livre de vibração.

O título foi estipulado como sendo a maior diluição do soro ainda capaz de apresentar aglutinação, com visualização de pequena rede de células agregadas ao redor do pequeno botão de hemácias sedimentadas ${ }^{15} 25$. 
Sasaki AT, Hoshino-Shimizu S, Nakamura PM, Vaz AJ, Camargo ED. Silva MV. Sorodiagnóstico da doença de Chagas: novo reagente para o teste de hemaglutinação indireta (THAI IAL). Revista da Sociedade Brasileira de Medicina Tropical 29:137-144, mar-abr, 1996.

Os testes foram sempre efetuados na presença de 3 soros-padrão positivo de títulos baixo, médio e elevado e 2 soros-padrão negativo.

Para o controle dos reagentes, foram ensaiadas hemácias sensibilizadas e tampão diluente; e para controle de soros, foram utilizadas hemácias não sensibilizadas controle.

\section{Soros}

Foram analisados 137 soros, incluindo 50 soros de pacientes chagásicos, clínica e laboratorialmente comprovados, provenientes do Serviço Social da Indústria (SESI - Departamento Regional de São Paulo, Divisão de Assistência Social, Subdivisão de Epidemiologia, Serviço de Laboratório); 23 soros de indivíduos clinicamente sadios; 64 soros de pacientes com outras afecções, que entram no diagnóstico diferencial da doença de Chagas: leishmaniose (20), artrite reumatóide (7), malária (10), esquistossomose mansônica (4), toxoplasmose aguda (4), blastomicose sul-americana (7) e sífilis (12).

\section{Outros testes imunológicos}

A comprovação laboratorial da doença de Chagas foi realizada pelos testes: imunofluorescência indireta (TIFI) executada de acordo com a técnica descrita por Camargo ${ }^{7}$, hemaglutinação indireta (THAI) utilizando hemácias humanas tipo "O" $\mathrm{Rh}$ negativo, realizada de acordo com Hoshino-Shimizu e cols" ${ }^{16}$, e "kit"comercial de THAI (Biolab Diagnóstica S/A, Brasil), que emprega reagente preparado com hemácias não especificadas de aves.

\section{Reprodutibilidade do reagente de THAI $^{\mathrm{IAL}}$}

Para o estudo da reprodutibilidade de resultados intra e inter-teste do THAI ${ }^{\mathrm{IAL}}$, foi utilizado um painel de 32 soros-padrão (16 positivos e 16 negativos), tendo títulos conhecidos e considerados de referência, procedendo-se dois ensaios no mesmo dia e em dias diferentes, respectivamente. $O$ limite de variabilidade (LV) foi obtido através dos dados fornecidos por 32 testes realizados com sorospadrão positivo, baseado na fórmula $L V=d p x$ 1,96 , onde dp corresponde à média dos desviospadrão obtidos nos diferentes ensaios contra o referido painel de soros ${ }^{18}$.

$\mathrm{O}$ estudo da reprodutibilidade de 5 diferentes lotes do reagente de THAI ${ }^{\text {IAL }}$ foi executado com 20 soros-padrão ( 10 positivos e 10 negativos), onde a variação foi verificada do mesmo modo descrito anteriormente.

\section{Estabilidade}

O reagente de $\mathrm{THAl}^{\mathrm{IAL}}$ foi dividido em alíquotas e conservado à temperatura de $37^{\circ} \mathrm{C} \mathrm{e}$ $4^{\circ} \mathrm{C}$. A estabilidade foi investigada com análises periódicas, quanto à sua reatividade contra um painel de 7 soros-padrão positivos e 2 soros-padrão negativos. Os dados foram analisados por método de controle de qualidade ${ }^{18}$, em termos de desviopadrão, sendo que o limite de variabilidade estipulado fundamentou-se nos ensaios intra e interteste.

\section{Desempenho diagnóstico}

O desempenho diagnóstico de THAI ${ }^{\mathrm{IAL}}$ expressos, em termos de sensibilidade, especificidade, valores preditivos positivos e negativos, e eficiência, foi determinado segundo conceitos de Galen e col ${ }^{12}$ e de Griner e cols ${ }^{13}$.

\section{RESULTADOS}

Na técnica proposta, foram utilizadas hemácias de ganso macho e fêmea fixadas com p-formaldeído a $10 \%$. Os resultados obtidos com hemácias do macho assim tratadas foram reprodutíveis por um período de até dois meses, quando conservadas a $4^{\circ} \mathrm{C}$, o mesmo não acontecendo com as das fêmeas. Não foi observada variação entre diferentes lotes de hemácias do macho, todavia a limitação de tempo foi persistente. As alterações ocorridas após dois mêses foram aglutinações que ocorreram em contacto dessas hemácias com alguns soros.

A concentração protéica do extrato antigênico preparado a partir de $100 \mathrm{mg}$ de peso úmido de parasita foi de $2.750 \mu \mathrm{g} / \mathrm{ml}$.

Os resultados da titulação em "bloco" do antígeno $(3 \mu \mathrm{g} / \mathrm{ml}$ a $100 \mu \mathrm{g} / \mathrm{ml})$ e do ácido tânico $(0,01 \mathrm{mg} / \mathrm{ml}$ a $0,5 \mathrm{mg} / \mathrm{ml})$, utilizando soros-padrão positivo e negativo, indicaram que as concentrações de ácido tânico a $0,1 \mathrm{mg}$ e de antígeno a $9 \mu \mathrm{g} / \mathrm{ml}$ eram 
Sasaki AT, Hoshino-Shimizu S, Nakamura PM, Vaz AJ, Camargo ED, Silva MV. Sorodiagnóstico da doença de Chagas: novo reagente para o teste de hemaglutinação indireta (THAI ${ }^{I A L}$ ). Revista da Sociedade Brasileira de Medicina Tropical 29:137-144, mar-abr, 1996.

as mais adequadas para o teste. Foram escolhidas para uso as concentrações de ácido tânico de $0,1 \mathrm{mg} / \mathrm{ml}$ e de antígeno $9 \mu \mathrm{g} / \mathrm{ml}$.

Não foi observada inespecificidade significativa com o soro-padrão negativo em nenhuma das concentrações estudadas de ácido tânico e antígeno.

Para a melhor fixação de antígeno às hemácias foram ensaiadas diferentes concentrações de glutaraldeído. Os dados mostraram que os resultados foram semelhantes em todas as concentrações estudadas, variando de $0,01 \%$ a $0,6 \%(\mathrm{v} / \mathrm{v})$. No entanto, na ausência de glutaraldeído, a reatividade do soro-padrão positivo foi menor. A concentração de $0,1 \%$ do glutaraldeído foi então escolhida para a pós-fixação do reagente.

Verificou-se ação estabilizadora mais eficaz do glicerol nas concentrações de $10 \%$ até $50 \%$, sendo que as de $40 \%$ e $50 \%$, preservaram a reatividade do reagente por mais de 90 dias a $4^{\circ} \mathrm{C}$ e por 75 dias a $37^{\circ} \mathrm{C}$ (Figura 1).

O propilenoglicol também foi ensaiado em diferentes concentrações $(10 \%$ a $50 \%)$ e produziu melhores resultados a $30 \%$. Esse estabilizante conferiu também estabilidade ao reagente, por cerca de 30 dias a temperatura de $37^{\circ} \mathrm{C}$. À temperatura de $4^{\circ} \mathrm{C}$, a durabilidade do reagente foi de três meses.

Da mesma forma, foi ensaiado o reagente contendo etilenoglicol ( $10 \%$ a $50 \%)$ em diferentes concentrações, e observou-se melhor ação estabilizadora quando o reagente foi mantido a $4^{\circ} \mathrm{C}$, cerca de 70 dias, com a concentração de $20 \%$. $\mathrm{Na}$ temperatura de $37^{\circ} \mathrm{C}$, não foram observados resultados satisfatórios, verificando-se autoaglutinação já no segundo dia.

Nos testes com os sais permanganato de potássio, dicromato de potássio e EDTA dissódico, nas concentrações variando desde $0,01 \%$ a $1 \%$, verificou-se a estabilização desses reagentes quando mantidos a $4^{\circ} \mathrm{C}$, mas a $37^{\circ} \mathrm{C}$ os resultados não foram satisfatórios.

As melhores concentrações de silicone e arlacel, suficientes para produzir a ação anti-espumante desejada, foram $0,08 \%$ e $0,06 \%$, respectivamente.

O reagrente obtido nas condições ótimas foi

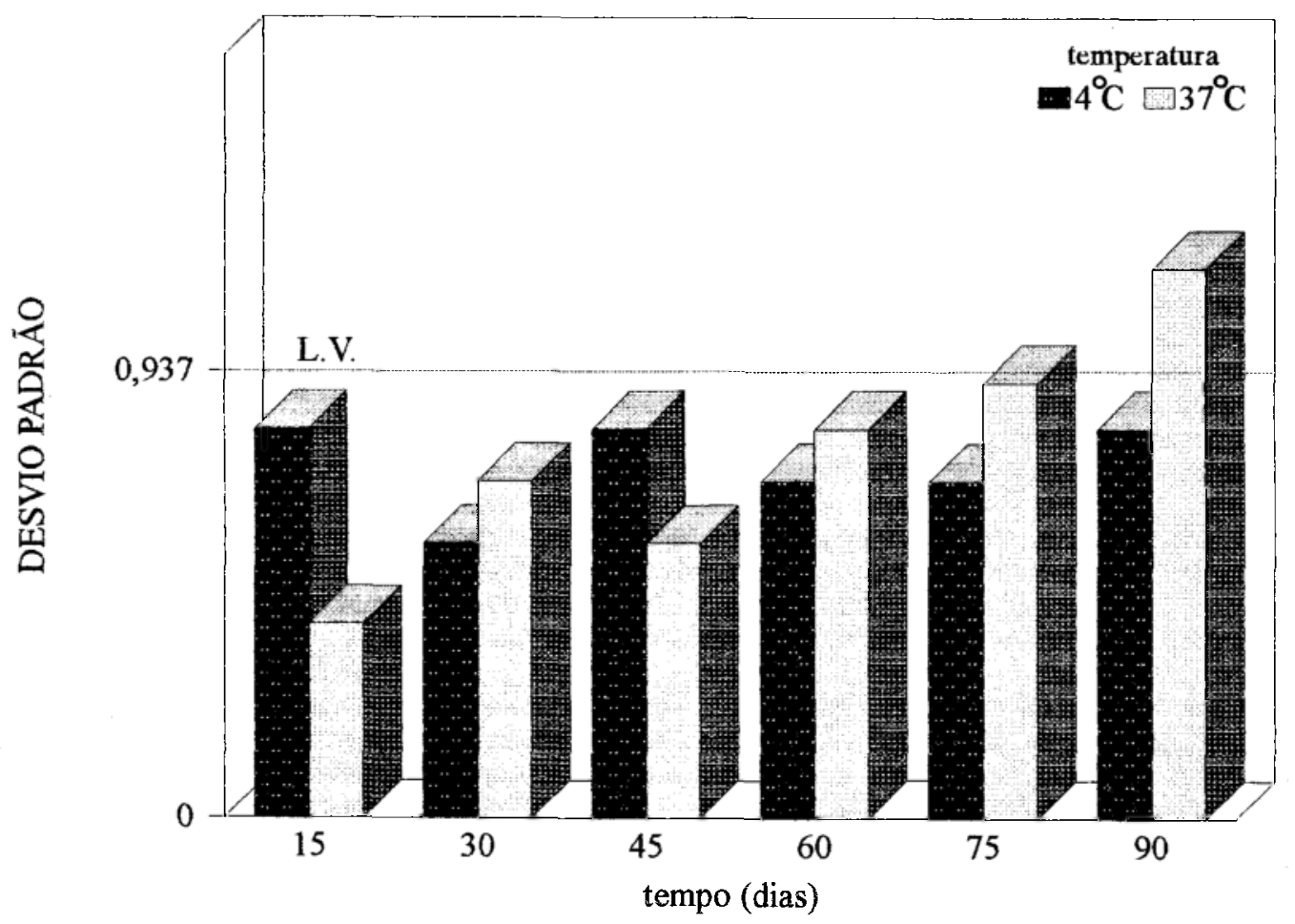

Figura 1 - Estabilidade do reagente THAI(LAL) quando conservado a $4^{\circ} \mathrm{C}$ e a $37^{\circ} \mathrm{C}$, por um periodo de 90 dias. Variabilidade expressa em termos de desvio padrão, no estudo de um painel de 7 soros positivos. LV=limite de variabilidade. 
Sasaki AT, Hoshino-Shimizu S, Nakamura PM, Vaz AJ, Camargo ED, Silva MV. Sorodiagnóstico da doença de Chagas: novo reagente para o teste de hemaglutinação indireta (THAI ${ }^{A L}$ ). Revista da Sociedade Brasileira de Medicina Tropical 29:137-144, mar-abr, 1996.

estudado quanto à reprodutibilidade intra e interteste no THAI ${ }^{\mathrm{IAL}}$, e os dados mostraram que as variações apresentadas em termos de desvio-padrão encontravam-se abaixo do valor limite de variabilidade $(0,937)$, e assim sendo todos os resultados foram considerados aceitáveis. No estudo da reprodutibilidade de partidas do reagente de THAI ${ }^{\mathrm{IAL}}$, os resultados foram negativos contra os soros-padrão negativos e a variação de títulos dos 10 soros-padrão positivos, expressa em desviopadrão foi de 0 a 0,667 , não excedendo também o valor limite de variabilidade estipulado.

A Figura 2, mostra os títulos de anticorpos dos soros dos grupos de indivíduos chagásicos, de indivíduos clinicamente sadios e de indivíduos com outras afecções, resultantes do estudo de THAI IAL que utiliza o novo reagente. $O$ limiar de reatividade foi considerado como sendo 32, por fornecer melhor nível de discriminação entre soros de chagásicos e não chagásicos.

As características diagnósticas apresentadas por THAI ${ }^{\mathrm{IAL}}$, THAI utilizando reagente de hemácias

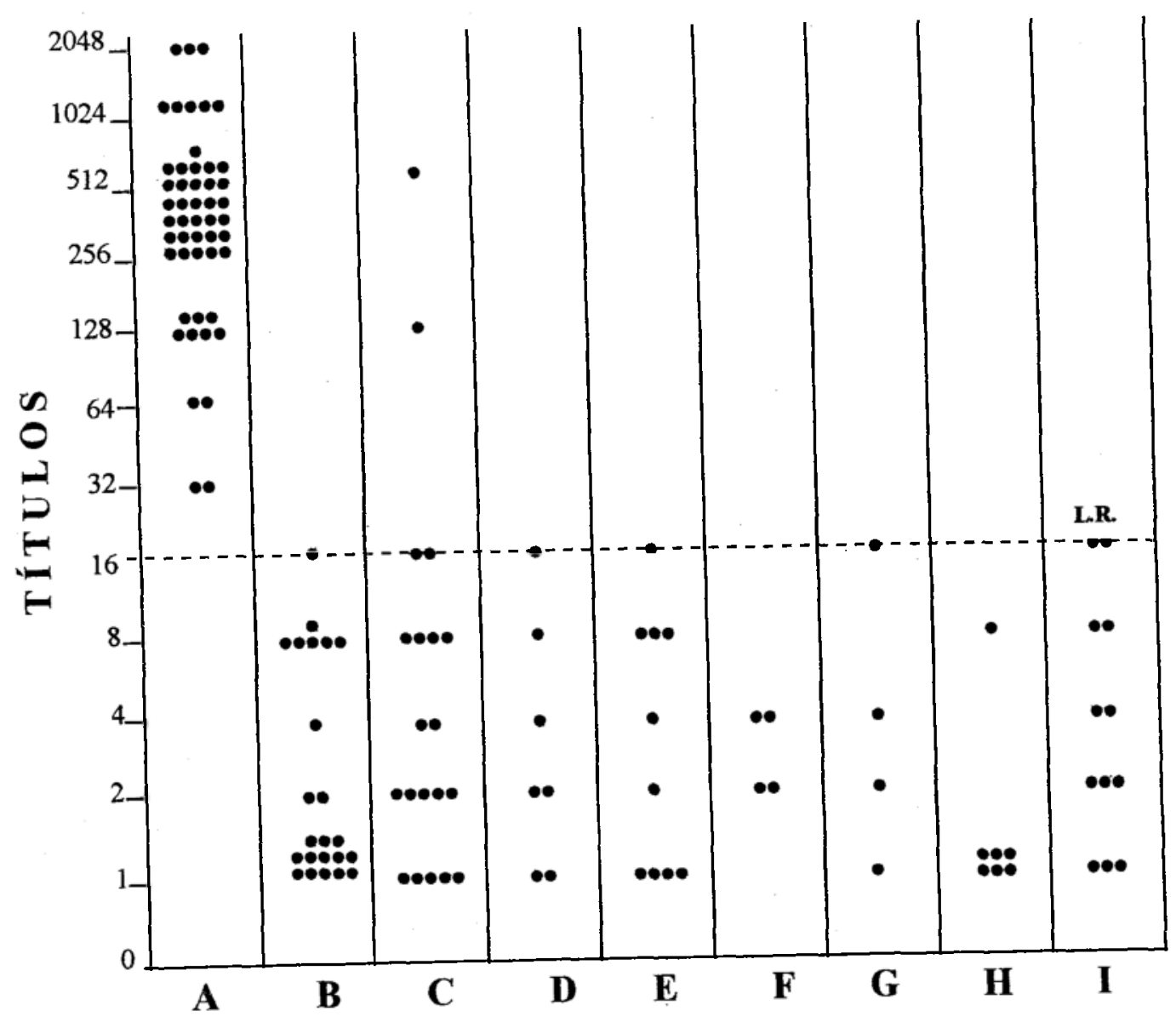

LR: limite de reatividade.

Soros: $\mathrm{A}=$ doença de Chagas, $\mathrm{B}=$ clinicamente sadios, $\mathrm{C}=$ leishmaniose, $\mathrm{D}=$ artrite reumatóide, $\mathrm{E}=$ malária, $\mathrm{F}=$ esquistossomose, $\mathrm{G}=$ toxoplasmose, $\mathrm{H}=$ blastomicose sul-americana, $\mathrm{I}=$ sífilis.

Figura 2 - Resultados obtidos no estudo de 137 soros de pacientes chagásicos e não chagásicos, no teste de hemaglutinação indireta (THAIIAL). 
Sasaki AT, Hoshino-Shimizu S, Nakamura PM, Vaz AJ, Camargo ED, Silva MV. Sorodiagnóstico da doença de Chagas: novo reagente para o teste de hemaglutinação indireta (THAI ${ }^{I A L}$ ). Revista da Sociedade Brasileira de Medicina Tropical 29:137-144, mar-abr, 1996.

humanas, e reagente de procedência comercial, no estudo de 137 soros de chagásicos e não chagásicos estão apresentadas na Tabela 1 , de forma comparativa.

A concordância foi de $100 \%$ entre estes testes, além de os níveis detectados de anticorpos antiT.cruzi serem também muito semelhantes fornecendo a média geométrica dos títulos de $8,3( \pm 1,3)$, $8,1( \pm 1,4)$ e $7,9( \pm 1,4)$ para os testes acima referidos, respectivamente.

Tabela 1 - Desempenho diagnóstico dos testes de hemaglutinação indireta empregando diferentes tipos de reagentes, no estudo de 137 soros de pacientes chagásicos e não chagásicos.

\begin{tabular}{ccccccc}
\hline \multirow{2}{*}{ Teste } & $\begin{array}{c}\text { Tipo de } \\
\text { hemácias }\end{array}$ & Sensibilidade & Especificidade & Eficiência & \multicolumn{2}{c}{ Preditivo } \\
\hline \multirow{2}{*}{ THAI $^{\text {IAL }}$} & ganso & & & & \\
THAI & humana & 1,00 & 0,98 & 0,99 & negativo \\
THAI & ave & $(0,93-1,00)$ & $(0,92-0,99)$ & $(0,95-1,00)$ & $(0,87-0,99)$ & $(0,96-1,00)$ \\
(comercial) & & & & & & \\
\hline
\end{tabular}

\section{DISCUSSÃO}

Hemácias de ganso macho demonstraram que podem substituir com sucesso as hemácias humanas do tipo "O", Rh negativo, na produção de reagente para o teste de hemaglutinação indireta, destinado ao sorodiagnóstico da doença de Chagas.

Hemácias de ganso macho forneceram partidas reprodutíveis de suportes inertes necessários para a produção de reagente, ao passo que hemácias de fêmeas apresentaram partidas variáveis e, portanto, consideradas inadequadas. Provavelmente nas fêmeas, as hemácias sejam susceptíveis à influência de alteração hormonal cíclica.

Células de ganso tratadas com paraformaldeído, quando conservadas a $4^{\circ} \mathrm{C}$, tiveram durabiliclade de 2 meses, período este muito menor do que o das hemácias humanas que era de cerca de $2 \operatorname{anos}^{16}$. Esta diferença decorre possivelmente por causa das propriedades físico-químicas serem variadas por conta da espécie. A autoaglutinação que foi observada nas hemácias de ganso, após 2 meses de conservação a $4^{\circ} \mathrm{C}$, poderia ser explicada pela maior ligação das moléculas de aldeído à superfície das células, ocasionando a diminuição das cargas eletrostáticas negativas que são responsáveis pela dispersão celular ${ }^{22}$.

Em virtude deste achado inicial, que apontava diferenças entre as hemácias humanas e de ganso, procedeu-se a optimização das condições para o preparo do reagente com hemácias de ganso.

Os resultados, no entanto, mostraram que as condições ótimas do preparo do reagente não diferiram significativamente do reagente anterior no tocante a aspectos de taninização, sensibilização e tratamento final com glutaraldeído.

$\mathrm{O}$ antígeno de $T$. cruzi solubilizado com álcali continuou sendo empregado por sua grande estabilidade, conferida pela inativação de enzimas do próprio parasita, e desta forma evitando a inclusão de inibidores enzimáticos.

No estudo da conservação do reagente de HAI, objetivando a diminuição do custo do produto e o aspecto prático, foram excluílos processos de liofilização e congelamento, sendo o reagente mantido na forma líquida, pronto para o uso, nas temperaturas de $4-8^{\circ} \mathrm{C}$ e $37^{\circ} \mathrm{C}$. Supunha-se que à temperatura de $37^{\circ} \mathrm{C}$, o processo de deterioração ou alteração do produto poderia ser acelerado. Desta forma, o principal fator limitante na escolha do constituinte da solução conservante foi a durabilidade do reagente à temperatura de $37^{\circ} \mathrm{C}$, freqüente em algumas regiões de nosso meio. Como previsto, a durabilidade dos reagentes foi sempre superior quando conservados a $4-8^{\circ} \mathrm{C}$, observando-se a reprodutibilidade e viabilidade do reagente escolhido, contendo glicerol a $40 \%$, pelo menos por um ano (dado não apresentado). 
Sasaki AT, Hoshino-Shimizu S, Nakamura PM, Vaz AJ, Camargo ED, Silva MV. Sorodiagnóstico da doença de Chagas: novo reagente para o teste de hemaglutinação indireta (THAI ${ }^{I A L}$ ). Revista da Sociedade Brasileira de Medicina Tropical 29:137-144, mar-abr, 1996.

A utilização do glicerol na conservação de amostras de soro está descrita na literatura ${ }^{828}$, mas não para o reagente de THAI. O glicerol tem sido empregado para diversas finalidades entre às quais, como umectante, lubrificante e anticongelante; propriedades estas que parecem contribuir para a manutenção da estabilidadle do produto. Além desse estabilizante, foram ensaiados o propilenoglicol e o etilenoglicol ${ }^{11}$, pela relativa semelhança na estrutura química, além de EDTA dissódico ${ }^{14}$, permanganato de potássio e dicromato de potássio, descritos por Nagasse-Sugahara ${ }^{21}$.

O estabilizante escolhido foi o glicerol a $40 \%$ dada à sua superior característica nas condiçōes impostas, ou seja, a maior durabilidade fornecida ao reagente de THAI $\left(75\right.$ dias a $37^{\circ} \mathrm{C}$ ) (Figura 1 ).

Silicone $e$ arlacel foram investigados para eliminar o problema da formação de espuma no momento de ressuspender o reagente para o uso, por causa da propriedade emulsificante do glicerol. Estas substâncias anti-espumas parecem não alterar as propriedades imunológicas do reagente, e ambas comportaram-se de maneira semelhante, contudo optamos pelo silicone devido a melhor missibilidade na solução conservadora.

Pode-se observar que todos os estabilizantes ensaiados apresentaram atividade conservadora satisfatória, o que permitirá, após estudos minuciosos, sua utilização em outras condições e sistemas antigênicos.

A análise dos resultados dos soros de pacientes chagásicos, indivíduos clinicamente normais e com outras afecções, realizada paralelamente com três tipos de reagente, mostrou concordância de $100 \%$. Nessa análise, foram observados dois casos de resultados falso positivos em todos os testes (Figura 2). Isso se deveu à reação cruzada peculiar aos antígenos utilizados, já que os dois casos reportaram infecção por Leishmania.

Os dados ainda preliminares obtidos por Western blot mostram que anticorpos eluídos do nosso reagente reconheceram principalmente bandas antigênicas do $T$. cruzi correspondentes a 33, 34, $39,42,50,59,75,77,81,96$ e $110 \mathrm{kDa}$.

Os resultados apresentados indicam que o teste realizado com o reagente desenvolvido para o diagnóstico imunológico da doença de Chagas é de elevada sensibilidade, especificidade, reprodutibilidade e concordância com os de THAI utilizando hemácias humanas e THAI comercial.

A estabilidade das células sensibilizadas foi considerada elevada, permitindo assim, que o reagente seja preparado em Laboratório Central e possa ser distribuído à Rede Pública de Laboratórios.

O THAI ${ }^{\mathrm{IAL}}$ poderá ser recomendado como um teste alternativo para triagem e diagnóstico de infecção pelo $T$. cruzi.

Por outro lado, os resultados deste estudo sugerem que o sistema pode ser utilizado na produção de reagentes para o diagnóstico de outras afecçôes.

\section{SUMMARY}

A new reagent was designed to the indirect hemagglutination test (IHAT ${ }^{A L}$ ), wilizing goose red blood cells as inert matrix and standardized for the field diagnosis of American trypanosomiasis. The objective was to substitute the byophilized or frozen reagent of IHAT produced routinely using human erythrocytes in the Adolfo Lutz Instilute (São Paulo/Brazil). The standardized reagent presented a long stability in liquid suspension, and was evaluated in 137 seruin samples from patient with and without Chagas'disease, by IHA TAL. The diagnostic performance of this test was similar to the IHAT utilizing human erythrocyles and to that of a commercial IHATkit. The sensitivity was 1.00 , specificity 0.98 , predictive value of positive 0.96 and of negalive 1.00. Different batches of reagent successively produced proved to be reproducible in a quality control method. The new reagent is more economic than the former reagent, it can be produced easily and incry be applicable to the seroepidemiologic studies.

Key-words: Goose red blood cells. IHAT Reagent. Chagas'disease. Serodiagnosis.

\section{AGRADECIMENTOS}

À Fundação Nacional de Saúde pelo auxílio financeiro, ao Prof. Dr. Antonio Walter Ferreira do Instituto de Medicina Tropical de São Paulo, ao Dr. José Fernando de Souza, Patologista Clínico do SESI, à Sheila Perez de Andrade, Técnica de Laboratório do Departamento Regional de São Paulo (Serviço de Laboratórios) pela colaboração na parte técnica e à Ângela Pires Brandão e Tokiko Kyomen Matsumoto, Pesquisadoras Científicas do Instituto Adolfo Lutz, por colaborarem no preparo deste manuscrito. 


\section{REFERÊNCIAS BIBLIOGRÁFICAS}

1. Almeida-Victor WR, Chiari E. Avaliação de antígenos do Trypanosoma cruzi para a reação de hemaglutinação indireta. I. Diferentes extratos antigênicos. Revista do Instituto de Medicina Tropical de São Paulo 29:178-182, 1987.

2. Andrade ALSS, Martinelli CMY, Juquetti AO, Oliveira OS, Silva SA, Zicker F. Triagem sorológica para o Trypanosoma cruzi entre doadores de sangue do Brasil Central Boletín de la Oficina Sanitaria Panamericana 113:19-25, 1992.

3. Bing DH, Weyand JGM, Stavitsky AB. Hemagglutination with aldehyde-fixed erythrocytes for assay of antigens and antibodies. Proceedings of the Society for Experimental Biology and Medicine 124:1146-1170, 1967.

4. Boyden SV. The adsorption of protein on erythrocytes treated with tannic acid and subsequent hemagglutination by anti-protein sera. Journal of Experimental Medicine 93:107-120, 1951.

5. Bukants SC, Rein CR, Kent JF. II. Preservation of sheep's blood in citrate dextrose mixtures (modified Alsever's solution) for use in the complement fixation reaction. Journal of Laboratory and Clinical Medicine 31 :394-399, 1946.

6. Butler WT. Hemagglutination with formalinized erythrocytes. Effect of bis-diazo-benzidine and tannic acid treatment on sensitization by soluble antigen. Journal of Immunology 90:663-671, 1963

7. Camargo ME. Fluorescent antibody test for the serodiagnosis of American trypanosomosis. Technical modification employing preserved culture forms of Trypanosoma cruzi in a slide test. Revista do Instituto de Medicina Tropical de São Paulo 8:227-234, 1966.

8. Camargo ME, Guimarães MCS. Conservação de alíquotas de soros de toxoplasmose e chagásicos por adição de glicerina (abstract). Proceedings of the 16th Congresso da Sociedade Brasileira de Medicina Tropical p.357, 1980.

9. Camargo ME, Hoshino-Shimizu S, Siqueira GRV. Hemagglutination with preserved, sensitized cells, a practical test for serologic diagnosis of american trypanosomiasis. Revista do Instituto de Medicina Tropical de São Paulo 15:81-85, 1973

10. Fernandes JF, Castellani $O$. Growth characteristics and chemical composition of Trypanosoma cruzi. Experimental Parasitology 18:195-202, 1966.

11. Frajola WJ, Maurukas J. A stable liquid human reference serum. Health Laboratory Science 13:25-33, 1976.

12. Galen RS, GambinoSR. Beyond normality: The predictive value and efficiency of medical diagnosis. Jön Willey, New York p.237, 1975.

13. Griner PF, Mayewski RJ, Mushlin AI, Greenland P. Selection and interpretation of diagnostic tests and procedures. Principles and applications. Annals of Internal Medicine 94:553-600, 1981.

14. Helou JH, Sakuda TM, Soares IC. Avaliaçāo de estabilizantes de soluçôes de peróxido de hidrogênio. Revista de Farmácia e Bioquímica da Universidade de São Paulo 23:11-18, 1987.

15. Hirata AA, Brandiss MW. Passive hemagglutination procedures for protein and polysaccharide antigens using erythrocytes by aldehydes. Journal of Immunology 100:641-646, 1968.

16. Hoshino-Shimizu S, Camargo ME, Nagasse TK. A stable polysaccharide hemagglutination reagent for the diagnosis of acute or recent Trypanosoma cruzi infections. Revista do Instituto de Medicina Tropical de São Paulo 20:208212,1978 .

17. Hoshino-Shimizu S, Camargo ME, Silva LC. Standardization of a hemagglutination test for schistosomiasis formalin-treated human erythrocytes. The American Journal of Tropical Medicine and Hygiene 19:463-470, 1970 .

18. Hoshino-Shimizu S, Nagasse-Sugahara TK, Castilho EA, Camargo ME, Shimizu T. Diagrama de verificación para evaluar reactivos de hamagglutinación usados en el diagnóstico de la enfermidade de Chagas. Boletín de la Oficina Sanitaria Panamericana $101: 465-476,1986$.

19. Lowry OH, Rosebrough NJ, Farr AL, Randall RJ. Protein measurement with the Folin phenol reagent. Journal of Biological Chenistry 193:265-275, 1951 .

20. Ministério da Saúde, Brasil. Nornas técnicas para a coleta, processamento e transfusão de sangue e derivados. Diário Oficial da Uniāo, Portaria $n^{\circ} 721$, de 11 de agosto de 1989.

21. Nagasse-Sugahara TK. Sorodiagnóstico da doença de Chagas: Desenvolvimento de um reagente estável para a reação de hemaglutinação passiva rápida. Tese de Mestrado, Universidade de São Paulo, São Paulo, 1993.

22. Pollack W, Hager HJ, Reckei R, Toren DA, Singher HO. A study of the forces involved in the second slage of hemagglutination. Transfusion 5:158-183, 1965.

23. Silva LHP, Nussenzweig V. Sobre uma eepa de Trypanosoma crizi altamente virulenta para o camundongo branco. Folia Clinica et Biológica 20:191-208, 1953.

24. Schmunis GA. Trypanosoma crizi, the etiologic agent of Chagas'disease: status in the blood supply in endenic and nonendemic countries. Transfusion 31:547-557, 1991 .

25. Stavitsky AB. Micromethods for the study of proteins and amibodies. 1. Procedure and general applications of hemagglutination and hemagglutination-inhibition reactions with tannic acid and protein treated red blood cells. Journal of Immunology 72:360-367, 1954.

26. Vitor RWA, Chiari E. Avaliação de antígeno do Trypanosoma cruzi para a reação de hemaglutinação indireta. Il. Antígenos de diferentes amostras e formas evolutivas. Revista do Instituto de Medicina Tropical de São Paulo 29:183-188, 1987.

27. Wendel S, Brener Z, Camargo ME, Rassi A. Chagas Disease (American Trypanosomiasis): Its Impact on Transfusion and clinical medicine. ISBTT Brasil'92, São Paulo, 1992.

28. Winslow CEA, Holland DF. The disinfectant action of glycerol in varying concentrations. In: Sollmann T (ed) A Manual of Pharmacology and its Applications to Therapeutics and Toxicology. W. B. Saunders, Philadelphia p. 90,1944 